ARTICLE

DOI: $10.1038 / s 41467-017-01099-x$

\title{
Organocatalytic enantio- and diastereoselective cycloetherification via dynamic kinetic resolution of chiral cyanohydrins
}

\author{
Naoki Yoneda ${ }^{1}$, Yuki Fujii ${ }^{1}$, Akira Matsumoto ${ }^{1}$, Keisuke Asano (id ${ }^{1}$ \& Seijiro Matsubara (i) ${ }^{1}$
}

Enantioselective approaches to synthesize six-membered oxacycles with multiple stereogenic centres are in high demand to enable the discovery of new therapeutic agents. Here we present a concise organocatalytic cycloetherification for the highly enantio- and diastereoselective synthesis of tetrahydropyrans involving simultaneous construction of two chiral centres, one of which is fully substituted. This method involves dynamic kinetic resolution of reversibly generated chiral cyanohydrins. A chiral bifunctional organocatalyst selectively recognizes a specific chair-like conformation of the intermediate, in which the small steric effect of the linear cyano group as well as its anomeric effect play important roles in controlling stereoselectivity. The products offer additional utility as synthetic intermediates because the cyano group can be further transformed into a variety of important functional groups. This strategy provides a platform to design efficient approaches to obtain a wide range of optically active tetrahydropyrans, which are otherwise synthetically challenging materials.

\footnotetext{
${ }^{1}$ Department of Material Chemistry, Graduate School of Engineering, Kyoto University, Kyotodaigaku-Katsura, Nishikyo, Kyoto 615-8510, Japan. Correspondence and requests for materials should be addressed to K.A. (email: asano.keisuke.5w@kyoto-u.ac.jp)

or to S.M. (email: matsubara.seijiro.2e@kyoto-u.ac.jp)
} 
$\mathrm{T}$ he relative stereochemistry of saturated six-membered cyclic compounds has become one of the most established concepts in the conformational analysis of organic molecules since the pioneering work of Barton ${ }^{1}$ and Hassel ${ }^{2}$. The saturated rings generally adopt stable chair conformations of unstrained $\mathrm{sp}^{3}$ hybrid atoms, with bulky substituents preferring to reside in equatorial positions to minimize steric clashes. Effective orbital interactions can also stereoelectronically control the relative configurations. Additionally, the absolute configurations of these frameworks are also a good opportunity for interaction with chiral hosts. In fact, optically active tetrahydropyrans (saturated six-membered oxacycles) are ubiquitous scaffolds in a wide range of bioactive compounds ${ }^{3-6}$, and their biological activities are strongly affected by their absolute stereochemistry. Thus, optically active derivatives are expected to have unexploited pharmaceutical activities; however, the lack of a simple robust method for their enantioselective synthesis has limited their development. In particular, as the enantio- and diastereoselective construction of multiple stereocentres in a single operation often poses a formidable challenge, it remains desirable to develop a concise, efficient method for the asymmetric installation of more than one chiral centre in tetrahydropyrans.

Cycloetherification of secondary or tertiary alcohols bearing an unsaturated moiety affords oxacycles containing two stereogenic centres via kinetic resolution of the racemic alcohols ${ }^{7-9}$ (Fig. 1a). Cyclization via dynamic kinetic resolution involving epimerization of chiral alcohols, enabling quantitative yields of the desired product, is more desirable; however, it has not yet been achieved. Epimerization of tertiary alcohols, which cannot be oxidized, requires especially harsh reaction conditions that are not suitable for asymmetric catalysis. To realize the cyclization of chiral tertiary alcohols via dynamic kinetic resolution, we propose a process involving reversible addition of a carbon nucleophile to ketones followed by cyclization ${ }^{10}$, leading to the efficient simultaneous construction of two stereogenic centres, including a tetrasubstituted chiral carbon (Fig. 1b). Furthermore, to accomplish the stereoselective construction of a tetrasubstituted chiral centre, which has been a long-standing challenge in organic synthesis ${ }^{11-13}$, we aimed to use a small electronegative carbon nucleophile. These features favour the introduction of the substituent adjacent to the heteroatom in an axial position in a six-membered oxacycle, enabling weaker 1,3-diaxial interactions as well as a favourable orbital interaction with the oxygen atom (anomeric effect) ${ }^{14}$.

\section{Results}

Reaction design. Based on the previously mentioned concepts, we selected hydrogen cyanide as a suitable carbon nucleophile because the stereoselective cyanation of ketones is an efficient method to construct tetrasubstituted chiral centres ${ }^{15-31}$, and the cyano group is known to have a small A value (conformational energy) $)^{32}$ and is capable of inducing an anomeric effect because of its electronegativity ${ }^{33-35}$. The diverse chemistry of the cyano group also expands the utility of the resulting products as synthetic intermediates ${ }^{36,37}$. Thus, the proposed dynamic kinetic resolution of chiral cyanohydrin intermediates, which are generated reversibly in situ, accompanied by an asymmetric intramolecular oxy-Michael addition ${ }^{38-48}$ mediated by bifunctional organocatalysts ${ }^{49-53}$, should enable a concise enantioselective synthesis of tetrahydropyrans with two chiral centres, including one fully substituted stereogenic centre (Fig. 2a). A chiral bifunctional organocatalyst can hydrogen bond to a specific conformation from the isomers generated during interconversions between both enantiomers of the intermediates in various conformations ${ }^{54}$. This complex immediately catalyses the subsequent asymmetric oxy-Michael addition from the recognized chair-like conformation with the cyano group in the axial position (A), also favoured by the weak 1,3-diaxial interactions and anomeric effect, to simultaneously generate two stereogenic centres (Fig. 2b). The resulting cyclic structures are found in a variety of bioactive agents ${ }^{3-6}$; the functionality of the cyano group has not only been used for further transformations in the synthesis of important compounds ${ }^{55-60}$, but also plays a major role in their biological activities ${ }^{61-63}$.

Optimization of reaction conditions. We initially investigated a model system consisting of bis-ketone 1a, acetone cyanohydrin (2) and $10 \mathrm{~mol} \%$ of cyclohexanediamine-based aminothiourea catalyst $4 \mathbf{a}$ in $\mathrm{CH}_{2} \mathrm{Cl}_{2}$ at $25^{\circ} \mathrm{C}$. As expected, the tetrahydropyran product was obtained quantitatively with excellent enantio- and diastereoselectivity (Table 1, entry 1). Catalyst $4 \mathbf{a}$, bearing a piperidyl group, was shown to be more effective to obtain higher reactivity and stereoselectivity than catalyst $\mathbf{4 b}$ (Table 1, entries 1

\section{a}

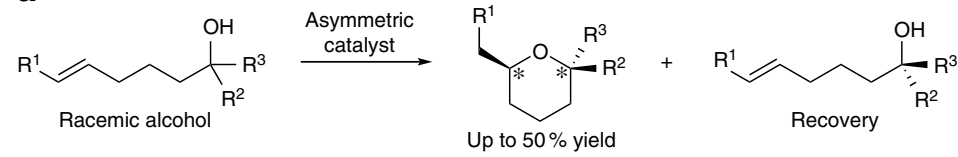

b

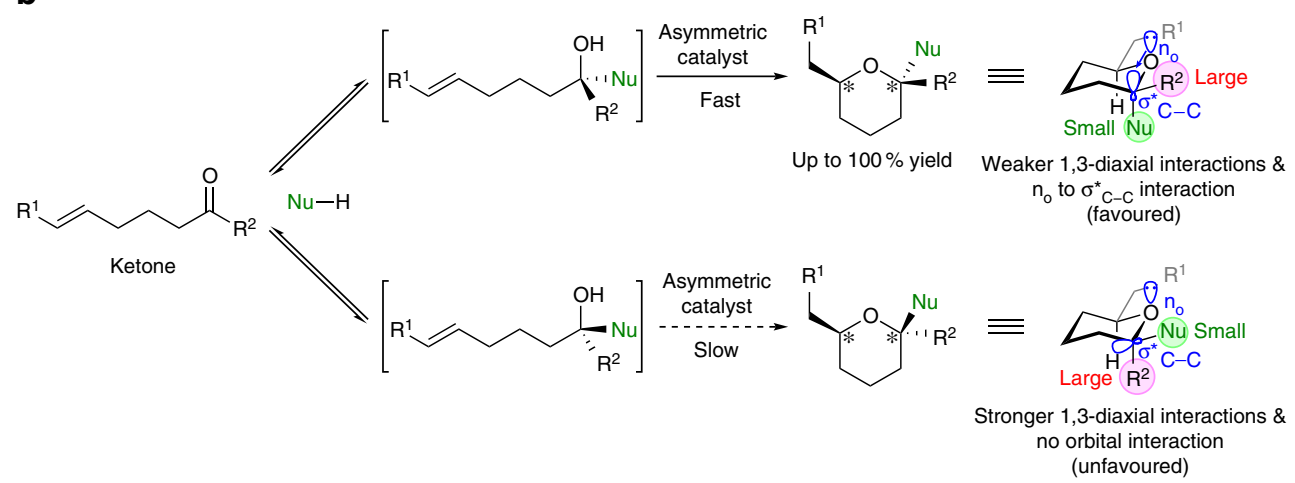

Fig. 1 Simultaneous construction of two stereogenic centres in tetrahydropyrans. a Cycloetherification via kinetic resolution of racemic alcohols. b Cycloetherification via dynamic kinetic resolution involving reversible addition of a carbon nucleophile to ketones 
a

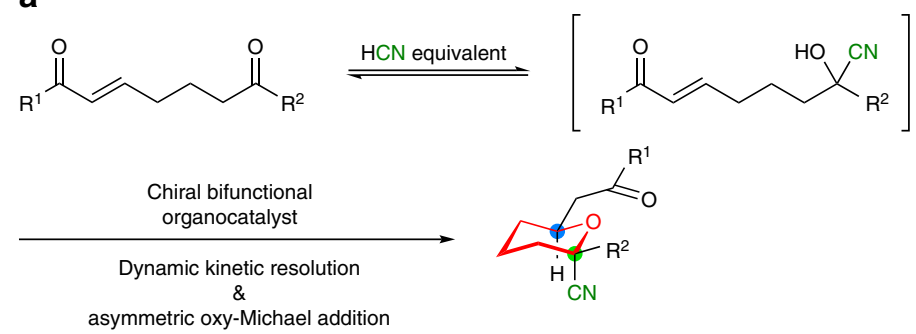

b

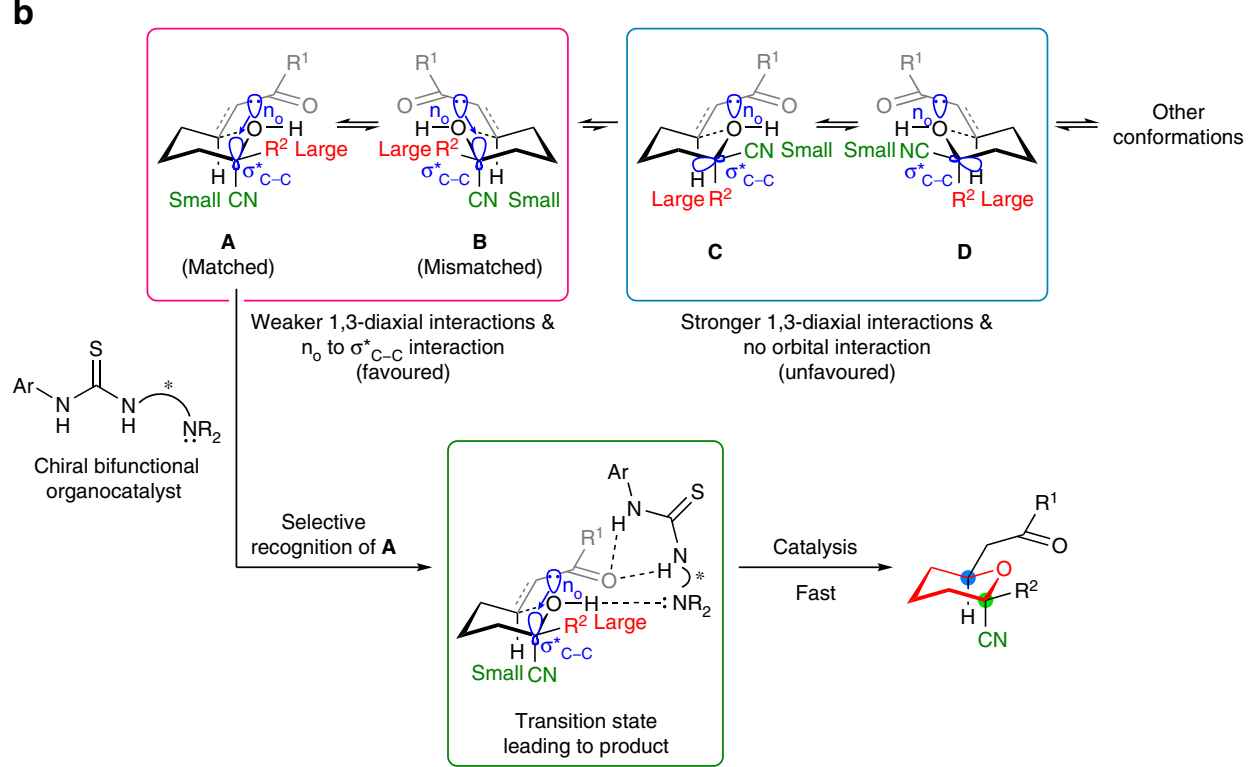

Fig. 2 Reaction design for cycloetherification via dynamic kinetic resolution. a Intramolecular oxy-Michael addition via dynamic kinetic resolution through reversible generation of chiral cyanohydrins. $\mathbf{b}$ Rationale for the proposed strategy

and 2). Catalyst 4c, which has a significantly less basic nitrogen atom, was not active, implying that the bifunctionality of catalysts containing amino and thiourea groups is important in this transformation (see also Supplementary Fig. 1-3). Cinchona alkaloid-derived aminothiourea catalysts were also shown to be effective, albeit with slightly lower reactivities and stereoselectivities (Table 1, entries 4-7). Alternative cyanide sources were also investigated. Trimethylsilyl cyanide in the presence of 2-propanol, which is known to generate hydrogen cyanide in $\operatorname{situ}^{29}$, gave the same stereoselectivity but a slightly lower yield (Table 1, entry 8). The use of trimethylsilyl cyanide alone afforded the product with the same stereoselectivity but a much lower yield (Table 1, entry 9). Solvent optimization studies identified $\mathrm{CH}_{2} \mathrm{Cl}_{2}$, $\mathrm{CHCl}_{3}$, and hydrocarbon solvents as affording especially high stereoselectivities with good yields (Table 1, entries 1, 10-12), while the use of polar solvents, which generally decrease anomeric effects, gave decreased yields and diastereoselectivities albeit with high enantioselectivities observed for both diastereomers (Table 1, entries 13-17). The reaction could also be carried out using a smaller amount of $\mathbf{2}$ and lower catalyst loading of $\mathbf{4 a}$, giving the same excellent stereoselectivity with a slight decrease of yield (Table 1, entry 18).

Substrate scope. With the optimized conditions (10 mol \% catalyst $4 \mathrm{a}$ in $\mathrm{CH}_{2} \mathrm{Cl}_{2}$ at $25^{\circ} \mathrm{C}$ ) in hand, we then explored the substrate scope (Fig. 3; see also Supplementary Fig. 4-6). Both electron-rich and -poor enones were tolerated, affording the corresponding products in high yields with good stereoselectivities (Fig. 3, 3b and 3c; see also Supplementary Fig. 7). An enone bearing a heterocyclic ring gave comparable results (Fig. 3, 3d), and an aliphatic enone provided the product in moderate yield with good stereoselectivity (Fig. 3, 3e). Furthermore, an $\alpha, \beta$ unsaturated thioester, which is useful for further transformations ${ }^{40}$, afforded the product in good yield with high stereoselectivity (Fig. 3, 3f). We went on to investigate the substituents that could be tolerated on the ketone (varying R'). A range of electron-rich and -poor aryl and heteroaryl ketones was tolerated, giving moderate to good yields, high enantioselectivities, and excellent diastereoselectivities (Fig. 3, 3g-3j). Aliphatic ketones were also successfully transformed, affording the desired products with high enantioselectivities and maintaining excellent diastereoselectivities (Fig. 3, 3k-3n). It is noteworthy that the methylsubstituted ketone yielded the corresponding tetrahydropyran with high enantio- and diastereoselectivities despite the relatively small difference in size between methyl and cyano groups, reinforcing that assistance was provided by the anomeric effect (Fig. 3, 3n; see also Supplementary Fig. 8).

Mechanistic insights. The absolute configuration of $\mathbf{3 a}$ was determined by X-ray analysis (Fig. 3, see Supplementary Fig. 122 for details), and the configurations of all other materials were assigned analogously. As expected, the cyano group is located in the axial position of the chair-like oxacycle, consistent with our rationale for the reaction design (Fig. 2b). Additionally, to examine whether cyanohydrin formation proceeded enantioselectively in the presence of a chiral bifunctional catalyst ${ }^{27,28}$, we carried out a reaction using ketone 5 , which lacks an $\alpha, \beta$-unsaturated carbonyl moiety, under the optimized conditions (Fig. 4). 


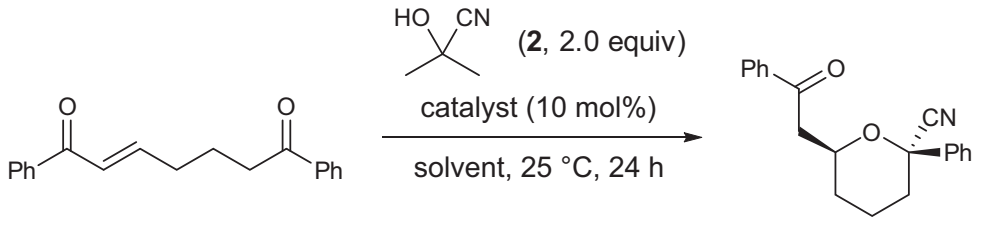

$1 a$

$3 a$

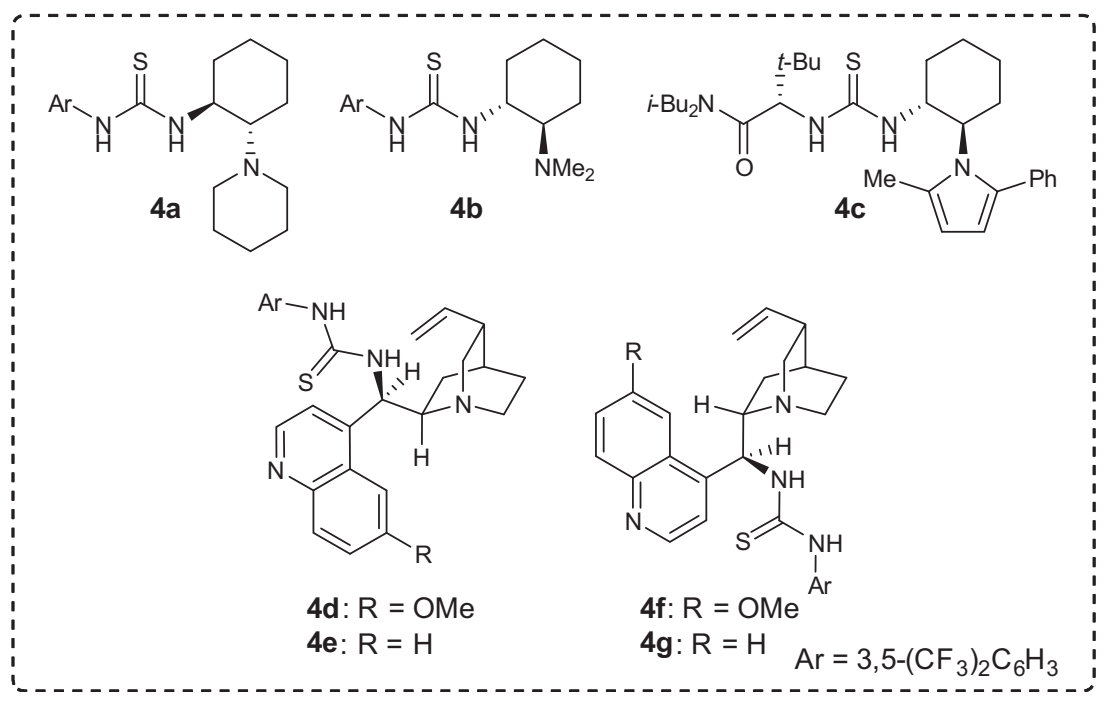

\begin{tabular}{|c|c|c|c|c|c|}
\hline Entry & Catalyst & Solvent & Yield (\%) & dr & ee (\%) \\
\hline$\overline{1}$ & $4 a$ & $\mathrm{CH}_{2} \mathrm{Cl}_{2}$ & 99 & $>20: 1$ & 97 \\
\hline 2 & $4 b$ & $\mathrm{CH}_{2} \mathrm{Cl}_{2}$ & 95 & $14: 1$ & -97 \\
\hline 3 & $4 c$ & $\mathrm{CH}_{2} \mathrm{Cl}_{2}$ & $<1$ & - & - \\
\hline 4 & 4d & $\mathrm{CH}_{2} \mathrm{Cl}_{2}$ & 89 & $14: 1$ & -92 \\
\hline 5 & $4 e$ & $\mathrm{CH}_{2} \mathrm{Cl}_{2}$ & 69 & $17: 1$ & -94 \\
\hline 6 & $4 f$ & $\mathrm{CH}_{2} \mathrm{Cl}_{2}$ & 72 & $11: 1$ & 93 \\
\hline 7 & $4 \mathrm{~g}$ & $\mathrm{CH}_{2} \mathrm{Cl}_{2}$ & 82 & $10: 1$ & 94 \\
\hline $8^{a}$ & $4 a$ & $\mathrm{CH}_{2} \mathrm{Cl}_{2}$ & 84 & $>20: 1$ & 97 \\
\hline $9^{b}$ & $4 a$ & $\mathrm{CH}_{2} \mathrm{Cl}_{2}$ & 14 & $>20: 1$ & 97 \\
\hline 10 & $4 a$ & $\mathrm{CHCl}_{3}$ & 93 & $>20: 1$ & 97 \\
\hline 11 & $4 a$ & Benzene & 93 & $>20: 1$ & 95 \\
\hline 12 & $4 a$ & Toluene & 90 & $>20: 1$ & 95 \\
\hline 13 & $4 a$ & $\mathrm{Et}_{2} \mathrm{O}$ & 59 & 20:1 & 93 \\
\hline 14 & $4 a$ & THF & 15 & 20:1 & 96 \\
\hline 15 & $4 a$ & EtOAc & 38 & $17: 1$ & 94 \\
\hline 16 & $4 a$ & $\mathrm{CH}_{3} \mathrm{CN}$ & 54 & 3.6:1 & $95\left(93^{d}\right)$ \\
\hline 17 & $4 a$ & $\mathrm{EtOH}$ & 23 & $9.2: 1$ & $96\left(88^{d}\right)$ \\
\hline $18^{c}$ & $4 a$ & $\mathrm{CH}_{2} \mathrm{Cl}_{2}$ & 84 & $>20: 1$ & 96 \\
\hline
\end{tabular}

While the cyanohydrin could not be isolated from the reaction using acetone cyanohydrin (2) because of the reversibility of ketone cyanation, the reaction using trimethylsilyl cyanide afforded the cyanosilylation product 7 with an enantioselectivity of only $17 \%$ ee (see also Table 1, entry 9 and Supplementary Fig. 9). These results imply that the enantioselectivity of the formation of 3 was not determined in the nucleophilic 1,2-addition step to form the cyanohydrin, but in a concerted manner via dynamic kinetic resolution involving the asymmetric oxy-Michael addition of the cyanohydrins, one enantiomer of which was selectively recognized and activated by the bifunctional organocatalyst.
Transformation of the product. The ability of the cyano group to be transformed into various functional groups ${ }^{36,37}$ further increases the value of our products as synthetic intermediates. Reaction of the cyano group enables a range of functional groups to be installed at the tetrasubstituted chiral centre in the pharmaceutically important tetrahydropyrans. The cyano group of $\mathbf{3 a}$ was converted to an aminomethyl group by treatment with lithium aluminium hydride, giving $\mathbf{9}$ after restoration of the carbonyl moiety without erosion of the optical purity (Fig. 5). Reaction with diisobutylaluminium hydride transformed the cyano group to a formyl group, a useful handle for further 


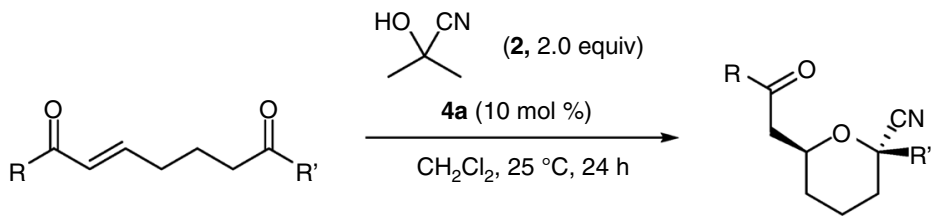

1

3

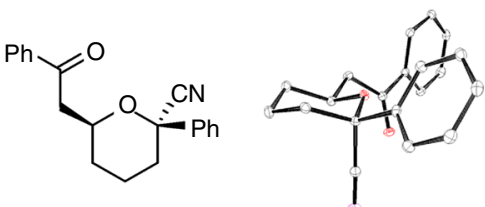

$3 a$

$99 \%$ $>20: 1 \mathrm{dr}$

$97 \%$ ee

ORTEP drawing of $\mathbf{3 a}$<smiles>N#C[C@]1(c2ccccc2)CCC[C@@H](CC(=O)c2cccs2)O1</smiles>

3d

$99 \%$

$>20: 1 \mathrm{dr}$

$97 \%$ ee<smiles>COc1ccc(C(=O)CC2CCC[C@](C#N)(c3ccccc3)O2)cc1</smiles>

3b

$99 \%$

$>20: 1 \mathrm{dr}$

$97 \%$ ee<smiles>N#C[C@]1(c2ccccc2)CCC[C@@H](CC(=O)c2ccc(C(F)(F)F)cc2)O1</smiles>

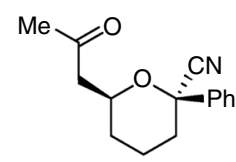

$3 e$

$58 \%$

$14: 1 \mathrm{dr}$

$91 \%$ ee<smiles>N#C[C@]1(c2ccccc2)CCCC(CC(=O)[Pb])O1</smiles>

$3 \mathbf{f}$

$70 \%$

$>20: 1 \mathrm{dr}$

$96 \%$ ee<smiles>C[C@]1(c2ccc(O)cc2)CCC[C@@H](CC(=O)c2ccccc2)O1</smiles><smiles>CC[C@@H]1CCC[C@@](C)(c2ccc(F)cc2)O1</smiles><smiles>C[C@]1(c2cccc3ccccc23)CCC[C@@H](CC(=O)c2ccccc2)O1</smiles><smiles>C[C@]1(c2cccs2)CCC[C@@H](CC(=O)c2ccccc2)O1</smiles>

$3 \mathbf{g}$
$55 \%$

$>20: 1 d r$ $98 \%$ ee<smiles>N#CC1(C#N)CCC[C@@H](CC(=O)c2ccccc2)O1</smiles>

3k

$59 \%$

$>20: 1 \mathrm{dr}$

$94 \%$ ee 3h

$89 \%$

$>20: 1 \mathrm{dr}$ $94 \%$ ee

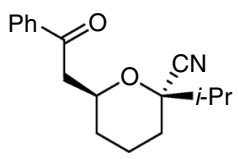

3I

$99 \%$

$95 \%$ ee

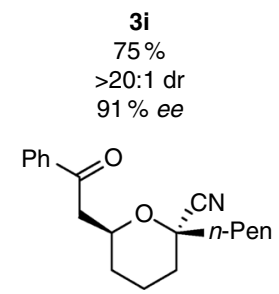

$3 \mathrm{~m}$
$99 \%$

$>20: 1 d r$

$82 \%$ ee
$3 c$

$89 \%$

$>20: 1 d r$

Fig. 3 Substrate scope. Reactions were run using $1(0.15 \mathrm{mmol}), 2(0.30 \mathrm{mmol})$, and $\mathbf{4 a}(0.015 \mathrm{mmol})$ in $\mathrm{CH}_{2} \mathrm{Cl}_{2}(0.30 \mathrm{ml})$. Yields represent material isolated after silica gel column chromatography. Diastereomeric ratios ( $\mathrm{dr}$ ) were determined by ${ }^{1} \mathrm{H}$ NMR spectroscopy. ${ }^{\star} \mathrm{Reaction}$ was run for $72 \mathrm{~h}$

transformation, affording $\mathbf{1 1}$ in good yield while maintaining the enantiomeric excess.

\section{Discussion}

We demonstrated a concise organocatalytic cycloetherification for the highly enantio- and diastereoselective synthesis of tetrahydropyrans with two chiral centres, one of which is a fully substituted stereogenic carbon centre. This method features an asymmetric intramolecular oxy-Michael addition and dynamic kinetic resolution involving reversible generation of chiral cyanohydrins. The proposed rationale for this transformation entails a chiral bifunctional organocatalyst selectively recognizing a specific chair-like conformation of the intermediate. The weak steric interaction and anomeric effect induced by the cyano group also play important roles in the control of stereoselectivity. The reaction products are useful synthetic intermediates because the

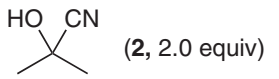

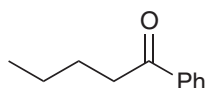

5<smiles>CCCCC(=O)c1ccccc1</smiles>

5

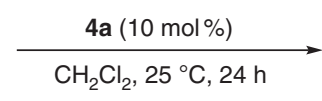

TMSCN (2.0 equiv)

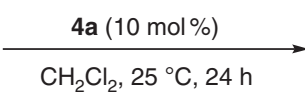

$\mathrm{CH}_{2} \mathrm{Cl}_{2}, 25^{\circ} \mathrm{C}, 24 \mathrm{~h}$

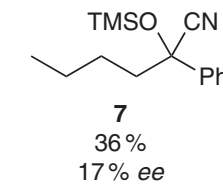

Fig. 4 Cyanohydrin formation under the optimized conditions. Reactions were run using $\mathbf{5}(0.15 \mathrm{mmol}), \mathbf{2}$ or trimethylsilylcyanide $(0.30 \mathrm{mmol})$, and 4a $(0.015 \mathrm{mmol})$ in $\mathrm{CH}_{2} \mathrm{Cl}_{2}(0.30 \mathrm{ml})$ 


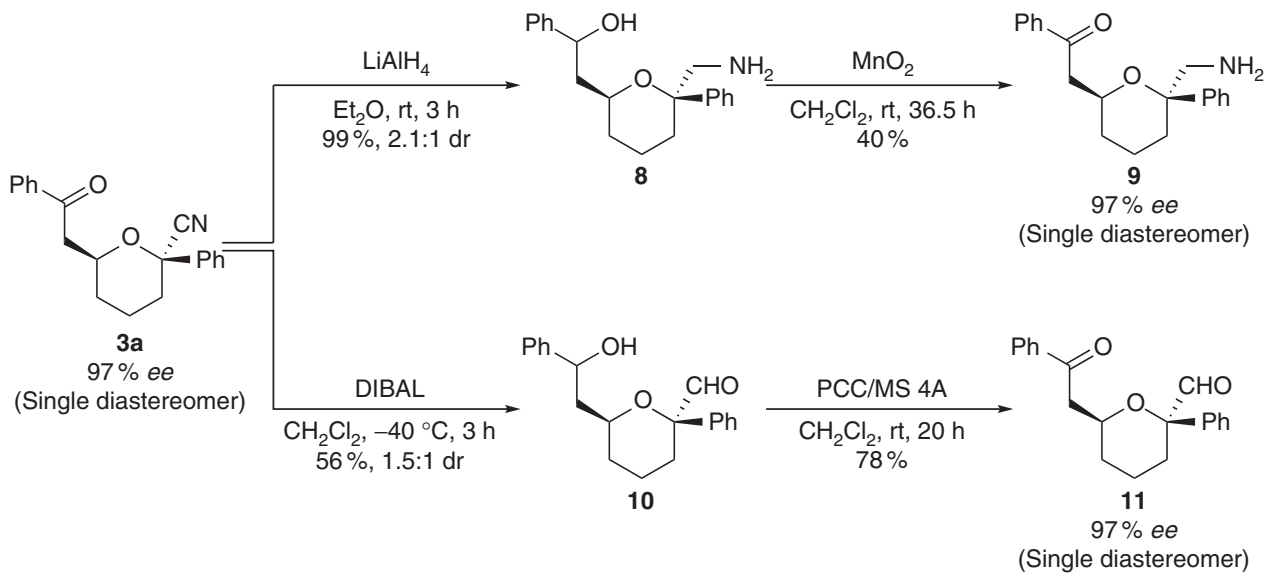

Fig. 5 Transformations of the cyano group in product 3a. Synthesis of $\mathbf{8}: \mathbf{3 a}(0.10 \mathrm{mmol})$ was treated with lithium aluminium hydride $(0.50 \mathrm{mmol})$ in $\mathrm{Et}{ }_{2} \mathrm{O}$ $(1.0 \mathrm{ml})$. Synthesis of $\mathbf{9}: \mathbf{8}(0.10 \mathrm{mmol})$ was treated with manganese dioxide $(1.0 \mathrm{mmol})$ in $\mathrm{CH}_{2} \mathrm{Cl}_{2}(2.0 \mathrm{ml})$. Synthesis of $\mathbf{1 0}$ : $\mathbf{3 a}(0.10 \mathrm{mmol})$ was treated with diisobutylaluminium hydride $(0.40 \mathrm{mmol})$ in $\mathrm{CH}_{2} \mathrm{Cl}_{2}(1.0 \mathrm{ml})$. Synthesis of $\mathbf{1 1}: \mathbf{1 0}(0.056 \mathrm{mmol})$ was treated with pyridinium chlorochromate (0.17 mmol) in $\mathrm{CH}_{2} \mathrm{Cl}_{2}(2.0 \mathrm{ml})$

cyano group can be further transformed into various functional groups to realize products that have potential as pharmaceutical agents. The current strategy provides an efficient route to a wide range of tetrahydropyran derivatives that are otherwise difficult to access, which will facilitate their evaluation. Further studies regarding the application of this methodology to expand the range of accessible optically active tetrahydropyrans bearing other substitution patterns are currently ongoing in our laboratory and will be reported in due course.

\section{Methods}

General procedure for the asymmetric synthesis of tetrahydropyrans 3. To a 5 - $\mathrm{ml}$ vial were added sequentially $\alpha, \beta$-unsaturated substrate $\mathbf{1}(0.15 \mathrm{mmol}), \mathrm{CH}_{2} \mathrm{Cl}_{2}$ $(0.30 \mathrm{ml})$, bifunctional catalyst $4 \mathrm{a}(0.015 \mathrm{mmol})$, and acetone cyanohydrin (2, $0.30 \mathrm{mmol}$ ). The mixture was stirred in an oil bath maintained at $25^{\circ} \mathrm{C}$ for $24 \mathrm{~h}$. The reaction mixture was subsequently diluted with hexane/EtOAc $(1: 1, \mathrm{v} / \mathrm{v})$, passed through a short silica gel pad to remove $4 \mathrm{a}$, and concentrated in vacuo to give the crude tetrahydropyrans 3 . Purification of the crude products by flash silica gel column chromatography using $\mathrm{CH}_{2} \mathrm{Cl}_{2} /$ hexane $(3: 1, \mathrm{v} / \mathrm{v})$ and then hexane/ EtOAc $(3: 1-10: 1, v / v)$ as an eluent afforded the corresponding tetrahydropyrans 3.

Data availability. Additional data supporting the findings described in this manuscript are available in the Supplementary Information. For full characterization data of new compounds and experimental details, see Supplementary Methods. For the ${ }^{1} \mathrm{H}$ and ${ }^{13} \mathrm{C}$ NMR spectra of new compounds, see Supplementary Figs. 10-99. For HPLC chromatogram profiles of the reaction products, see Supplementary Figs. 100-121. For an ORTEP drawing of 3a, see Supplementary Fig. 122. X-ray crystallographic data have also been deposited at the Cambridge Crystallographic Data Centre (http://www.ccdc.cam.ac.uk/) with the accession code CCDC 1566029. All other data are available from the authors upon reasonable request.

Received: 13 December 2016 Accepted: 15 August 2017

Published online: 09 November 2017

\section{References}

1. Barton, D. H. R. The conformation of the steroid nucleus. Experientia 6 , 316-320 (1950).

2. Hassel, O. Stereochemistry of cyclohexane. Quart. Rev. 7, 221-230 (1953).

3. Faul, M. M. \& Huff, B. E. Strategy and methodology development for the total synthesis of polyether ionophore antibiotics. Chem. Rev. 100, 2407-2473 (2000).

4. Kang, E. J. \& Lee, E. Total synthesis of oxacyclic macrodiolide natural products. Chem. Rev. 105, 4348-4378 (2005).

5. Lorente, A., Lamariano-Merketegi, J., Albericio, F. \& Álvarez, M. Tetrahydrofuran-containing macrolides: a fascinating gift from the deep sea. Chem. Rev. 113, 4567-4610 (2013).

6. Aho, J. E., Pihko, P. M. \& Rissa, T. K. Nonanomeric spiroketals in natural products: structures, sources, and synthetic strategies. Chem. Rev. 105, 4406-4440 (2005).
7. Yoneda, N., Matsumoto, A., Asano, K. \& Matsubara, S. Asymmetric cycloetherification via the kinetic resolution of alcohols using chiral phosphoric acid catalysts. Chem. Lett. 45, 1300-1303 (2016).

8. Vedejs, E. \& Jure, M. Efficiency in nonenzymatic kinetic resolution. Angew. Chem. Int. Ed. 44, 3974-4001 (2005).

9. Müller, C. E. \& Schreiner, P. R. Organocatalytic enantioselective acyl transfer onto racemic as well as meso alcohols, amines, and thiols. Angew. Chem. Int. Ed. 50, 6012-6042 (2011).

10. Gharpure, S. J., Prasad, J. V. K. \& Bera, K. Tandem nucleophilic addition/oxaMichael reaction for the synthesis of cis-2,6-disubstituted tetrahydropyrans. Eur. J. Org. Chem. 2014, 3570-3574 (2014).

11. Riant, O. \& Hannedouche, J. Asymmetric catalysis for the construction of quaternary carbon centres: nucleophilic addition on ketones and ketimines. Org. Biomol. Chem. 5, 873-888 (2007).

12. Shibasaki, M. \& Kanai, M. Catalytic enantioselective construction of tetrasubstituted carbons by self-assembled poly rare earth metal complexes. Org. Biomol. Chem. 5, 2027-2039 (2007).

13. Hatano, M. \& Ishihara, K. Recent progress in the catalytic synthesis of tertiary alcohols from ketones with organometallic reagents. Synthesis 2008, 1647-1675 (2008).

14. Juaristi, E. \& Cuevas, G. Recent studies of the anomeric effect. Tetrahedron 48, 5019-5087 (1992).

15. Gregory, R. J. H. Cyanohydrins in nature and the laboratory: biology, preparations, and synthetic applications. Chem. Rev. 99, 3649-3682 (1999).

16. North, M. Synthesis and applications of non-racemic cyanohydrins. Tetrahedron: Asymmetry 14, 147-176 (2003).

17. Brunel, J.-M. \& Holmes, I. P. Chemically catalyzed asymmetric cyanohydrin syntheses. Angew. Chem. Int. Ed. 43, 2752-2778 (2004).

18. Chen, F.-X. \& Feng, X. Asymmetric synthesis of cyanohydrins. Curr. Org. Synth. 3, 77-97 (2006).

19. Doyle, A. G. \& Jacobsen, E. N. Small-molecule H-bond donors in asymmetric catalysis. Chem. Rev. 107, 5713-5743 (2007).

20. North, M., Usanov, D. L. \& Young, C. Lewis acid catalyzed asymmetric cyanohydrin synthesis. Chem. Rev. 108, 5146-5226 (2008).

21. Khan, N. H., Kureshy, R. I., Abdi, S. H. R., Agrawal, S. \& Jasra, R. V. Metal catalyzed asymmetric cyanation reactions. Coord. Chem. Rev. 252, 593-623 (2008).

22. Gawronski, J., Wascinska, N. \& Gajewy, J. Recent progress in Lewis base activation and control of stereoselectivity in the additions of trimethylsilyl nucleophiles. Chem. Rev. 108, 5227-5252 (2008).

23. Denmark, S. E. \& Beutner, G. L. Lewis base catalysis in organic synthesis. Angew. Chem. Int. Ed. 47, 1560-1638 (2008).

24. Wang, J. et al. Asymmetric cyanation of aldehydes, ketones, aldimines, and ketimines catalyzed by a versatile catalyst generated from cinchona alkaloid, achiral substituted 2,2'-biphenol and tetraisopropyl titanate. Chem. Eur. J. 15, 11642-11659 (2009).

25. Wang, W., Liu, X., Lin, L. \& Feng, X. Recent progress in the chemically catalyzed enantioselective synthesis of cyanohydrins. Eur. J. Org. Chem. 2010, 4751-4769 (2010).

26. Murtinho, D. \& da Silva Serra, M. E. Organocatalysed cyanations of carbonyl compounds. Curr. Organocatal. 1, 87-106 (2014).

27. Hamashima, Y., Kanai, M. \& Shibasaki, M. Catalytic enantioselective cyanosilylation of ketones. J. Am. Chem. Soc. 122, 7412-7413 (2000). 
28. Fuerst, D. E. \& Jacobsen, E. N. Thiourea-catalyzed enantioselective cyanosilylation of ketones. J. Am. Chem. Soc. 127, 8964-8965 (2005)

29. Hatano, M., Yamakawa, K., Kawai, T., Horibe, T. \& Ishihara, K. Enantioselective cyanosilylation of ketones with lithium(I) dicyanotrimethylsilicate(IV) catalyzed by a chiral lithium(I) phosphoryl phenoxide. Angew. Chem. Int. Ed. 55, 4021-4025 (2016).

30. Tian, S.-K. \& Deng, L. A highly enantioselective chiral Lewis base-catalyzed asymmetric cyanation of ketones. J. Am. Chem. Soc. 123, 6195-6196 (2001).

31. Ogura, Y., Akakura, M., Sakakura, A. \& Ishihara, K. Enantioselective cyanoethoxycarbonylation of isatins promoted by a Lewis base-Brønsted acid cooperative catalyst. Angew. Chem. Int. Ed. 52, 8299-8303 (2013).

32. Stereochemistry of Organic Compounds (eds Eliel, E. L. \& Wilen, S. H.) Ch. 11 (John Wiley \& Sons, 1994).

33. Bauerfeldt, G. F., Cardozo, T. M., Pereira, M. S. \& da Silva, C. O. The anomeric effect: the dominance of exchange effects in closed-shell systems. Org. Biomol. Chem. 11, 299-308 (2013).

34. Bonin, M., Romero, J. R., Grierson, D. S. \& Husson, H.-P. 2-Cyano- $\Delta^{3}$ piperideines. 12. Stereochemistry of formation of $N$-benzyl-2-cyano- $\Delta^{3}$ piperideines and facile isomerization on alumina to 2 -cyano- $\Delta^{4}$-piperideines. A potentially general route to the synthesis of 2,6-disubstituted piperidine alkaloids. J. Org. Chem. 49, 2392-2400 (1984).

35. Amos, D. T., Renslo, A. R. \& Danheiser, R. L. Intramolecular [4+2] cycloadditions of iminoacetonitriles: a new class of azadienophiles for hetero Diels-Alder reactions. J. Am. Chem. Soc. 125, 4970-4971 (2003).

36. Friedrich, K. \& Wallenfels, K. in The Chemistry of the Cyano Group (ed. Rappaport, Z.) Ch. 2 (John Wiley \& Sons, 1970).

37. Fatiadi, A. J. in The Chemistry of Triple-Bonded Functional Groups Vol. 2 (eds Patai, S. \& Rappaport, Z.) Ch. 26 (John Wiley \& Sons, 1983).

38. Asano, K. \& Matsubara, S. Asymmetric catalytic cycloetherification mediated by bifunctional organocatalysts. J. Am. Chem. Soc. 133, 16711-16713 (2011).

39. Asano, K. \& Matsubara, S. Asymmetric synthesis of 1,3-dioxolanes by organocatalytic formal [3+2] cycloaddition via hemiacetal intermediates. Org. Lett. 14, 1620-1623 (2012).

40. Okamura, T., Asano, K. \& Matsubara, S. Organocatalytic asymmetric oxyMichael addition to a $\gamma$-hydroxy- $\alpha, \beta$-unsaturated thioester via hemiacetal intermediates. Chem. Commun. 48, 5076-5078 (2012).

41. Fukata, Y., Miyaji, R., Okamura, T., Asano, K. \& Matsubara, S. Asymmetric cycloetherifications by bifunctional aminothiourea catalysts: the importance of hydrogen bonding. Synthesis 45, 1627-1634 (2013).

42. Miyaji, R., Asano, K. \& Matsubara, S. Asymmetric chroman synthesis via an intramolecular oxy-Michael addition by bifunctional organocatalysts. Org. Biomol. Chem. 12, 119-122 (2014).

43. Yoneda, N., Hotta, A., Asano, K. \& Matsubara, S. Asymmetric oxy-Michael addition to $\gamma$-hydroxy- $\alpha, \beta$-unsaturated carbonyls using formaldehyde as an oxygen-centered nucleophile. Org. Lett. 16, 6264-6266 (2014).

44. Yoneda, N., Fukata, Y., Asano, K. \& Matsubara, S. Asymmetric synthesis of spiroketals with aminothiourea catalysts. Angew. Chem. Int. Ed. 54, 15497-15500 (2015)

45. Biddle, M. M., Lin, M. \& Scheidt, K. A. Catalytic enantioselective synthesis of flavanones and chromanones. J. Am. Chem. Soc. 129, 3830-3831 (2007).

46. Li, D. R., Murugan, A. \& Falck, J. R. Enantioselective, organocatalytic oxyMichael addition to $\gamma / \delta$-hydroxy- $\alpha, \beta$-enones: boronate-amine complexes as chiral hydroxide synthons. J. Am. Chem. Soc. 130, 46-48 (2008).

47. Kobayashi, Y., Taniguchi, Y., Hayama, N., Inokuma, T. \& Takemoto, Y. A powerful hydrogen-bond-donating organocatalyst for the enantioselective intramolecular oxa-Michael reaction of $\alpha, \beta$-unsaturated amides and esters. Angew. Chem. Int. Ed. 52, 11114-11118 (2013).

48. Maity, S., Parhi, B. \& Ghorai, P. Enantio- and diastereoselective synthesis of exo-peroxyacetals: an oranocatalyzed peroxyhemiacetalization/oxa-Michael addition cascade. Angew. Chem. Int. Ed. 55, 7723-7727 (2016).

49. Okino, T., Hoashi, Y. \& Takemoto, Y. Enantioselective Michael reaction of malonates to nitroolefins catalyzed by bifunctional organocatalysts. J. Am. Chem. Soc. 125, 12672-12673 (2003).

50. Vakulya, B., Varga, S., Csámpai, A. \& Soós, T. Highly enantioselective conjugate addition of nitromethane to chalcones using bifunctional cinchona organocatalysts. Org. Lett. 7, 1967-1969 (2005).

51. Hamza, A., Schubert, G., Soós, T. \& Pápai, I. Theoretical studies on the bifunctionality of chiral thiourea-based organocatalysts: competing routes to C-C bond formation. J. Am. Chem. Soc. 128, 13151-13160 (2006).

52. Connon, S. J. Organocatalysis mediated by (thio)urea derivatives. Chem.-Eur. J 12, 5418-5427 (2006).

53. Zhu, J.-L., Zhang, Y., Liu, C., Zheng, A.-M. \& Wang, W. Insights into the dual activation mechanism involving bifunctional cinchona alkaloid thiourea organocatalysts: an NMR and DFT study. J. Org. Chem. 77, 9813-9825 (2012).
54. Knowles, R. R. \& Jacobsen, E. N. Attractive noncovalent interactions in asymmetric catalysis: links between enzymes and small molecule catalysts. Proc. Natl. Acad. Sci. USA 107, 20678-20685 (2010).

55. Barrero, A. F., Alvarez-Manzaneda Roldán, E. J., Romera Santiago, J. L. \& Chahboun, R. Highly diastereoselective synthesis of manoyl oxide derivatives by $\mathrm{TiCl}_{4}$-catalyzed nucleophilic cleavage of ambracetal derivatives. Synlett $\mathbf{2 0 0 3}$, 2313-2316 (2003).

56. Tadanier, J. et al. 2-Deoxy-2-(substituted-methyl)analogs of $\beta$-Kdop. Carbohydr. Res. 201, 209-222 (1990).

57. Schweizer, F., Otter, A. \& Hindsgaul, O. Synthesis of sugar-fused GABAanalogs. Synlett 2001, 1743-1746 (2001).

58. Schweizer, F. \& Hindsgaul, O. Synthesis of a galacto-configured C-ketosidebased $\gamma$-sugar-amino acid and its use in peptide coupling reactions. Carbohydr. Res. 341, 1730-1736 (2006).

59. Pal, A. P. J., Gupta, P., Reddy, Y. S. \& Vankar, Y. D. Synthesis of fused oxa-aza spiro sugars from D-glucose-derived $\delta$-lactone as glycosidase inhibitors. Eur. J. Org. Chem. 2010, 6957-6966 (2010).

60. Yamada, H., Adachi, M. \& Nishikawa, T. Stereocontrolled synthesis of the oxathiabicyclo[3.3.1] nonane core structure of tagetitoxin. Chem. Commun. 49, 11221-11223 (2013).

61. Janero, D. A., Cohen, N., Burghardt, B. \& Schaer, B. H. Novel 6-hydroxy chroman-2-carbonitrile inhibitors of membrane peroxidative injury. Biochem. Pharmacol. 40, 551-558 (1990).

62. Ooiwa, H., Janero, D. R., Stanley, A. W. H. \& Downey, J. M. Examination of two small-molecule antiperoxidative agents in a rabbit model of postischemic myocardial infarction. J. Cardiovasc. Pharmacol. 17, 761-767 (1991).

63. Boscoboinik, D., Özer, N. K., Moser, U. \& Azzi, A. Tocopherols and 6-hydroxychroman-2-carbonitrile derivatives inhibit vascular smooth muscle cell proliferation by a nonantioxidant mechanism. Arch. Biochem. Biophys. 318, 241-246 (1995).

\section{Acknowledgements}

We thank Dr. Hiroyasu Sato (RIGAKU) and Professor Takuya Kurahashi (Kyoto University) for X-ray crystallographic analysis. This work was supported financially by the Japanese Ministry of Education, Culture, Sports, Science and Technology (15H05845 and 16K13994). K.A. also acknowledges the Asahi Glass Foundation, Toyota Physical and Chemical Research Institute, Tokyo Institute of Technology Foundation, the Naito Foundation, Research Institute for Production Development, the Tokyo Biochemical Research Foundation, the Uehara Memorial Foundation, the Kyoto University Foundation, and Kyoto University Research Development Program 2016. A.M. also acknowledges the Japan Society for the Promotion of Science for Young Scientists for fellowship support.

\section{Author contributions}

K.A. conceived and designed the study. S.M. supervised the project. N.Y., Y.F. and A.M. carried out the chemical experiments and analysed the data. K.A. wrote the manuscript. All authors discussed the results and commented on the manuscript.

\section{Additional information}

Supplementary Information accompanies this paper at doi:10.1038/s41467-017-01099-x.

Competing interests: The authors declare no competing financial interests.

Reprints and permission information is available online at http://npg.nature.com/ reprintsandpermissions/

Publisher's note: Springer Nature remains neutral with regard to jurisdictional claims in published maps and institutional affiliations.

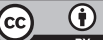

Open Access This article is licensed under a Creative Commons Attribution 4.0 International License, which permits use, sharing, adaptation, distribution and reproduction in any medium or format, as long as you give appropriate credit to the original author(s) and the source, provide a link to the Creative Commons license, and indicate if changes were made. The images or other third party material in this article are included in the article's Creative Commons license, unless indicated otherwise in a credit line to the material. If material is not included in the article's Creative Commons license and your intended use is not permitted by statutory regulation or exceeds the permitted use, you will need to obtain permission directly from the copyright holder. To view a copy of this license, visit http://creativecommons.org/ licenses/by/4.0/.

(C) The Author(s) 2017 